\title{
Atopic Dermatitis
}

\section{Juan Jose Luis Sienra-Monge, Elsy Maureen Navarrete-Rodriguez}

Hospital Infantil de Mexico Federico Gómez, Mexico

*Corresponding author: Elsy Maureen Navarrete-Rodriguez, Hospital Infantil de Mexico Federico Gómez, Mexico, Tel: 63945646; E-mail: elisiee21@hotmail.com

Received date: September 29, 2015; Accepted date: December 21, 2015; Published date: January 04, 2016

Copyright: (c) 2016 Sienra-Monge and Navarrete-Rodriguez. This is an open-access article distributed under the terms of the Creative Commons Attribution License, which permits unrestricted use, distribution, and reproduction in any medium, provided the original author and source are credited.

\section{Atopic dermatitis}

Atopic dermatitis is one of the most common causes of paediatric, dermatological and allergological consultation; it is characterized by chronic inflammation of the skin, affecting mainly paediatric patients $[1,2]$.

It is manifested mostly as a mild disease according to the SCORAD score of symptoms (less than 15). There is a minority of individuals who have severe manifestations which are not only a diagnostic, also a therapeutic challenge claiming many therapeutic resources. Although this condition is not life-threatening, results in a decrease in their life quality as well as their families, sleep disturbances, increased anxiety, family dysfunction and varying in intensity depending on the severity and comorbidities [3-5].The prevalence varies globally between $5-15 \%$ 6 and certainly there has been an increase in both prevalence and incidence of the disease [7] especially in Westernized countries.

Inside there are multiple aetiologies, constitutional, genetic, immunological and environmental factors, highlighting mutations and polymorphisms in filaggrin gene and pro-inflammatory interleukins $[2,8,9]$. The set of immunological disorders, skin barrier and environmental factors lead to increased inflammation through IL - 25, IL - 33 and TSLP directing the response towards a T cell-mediated helper type 2 (Th2) responses. TH2 phenotype through IL 4 and IL 13 induces a shift to IgE, which predisposes sensibilization and allergic response [10].

We have witnessed the arduous process of research that has been conducted in recent years in the study of atopic dermatitis and nevertheless the great advances of knowledge in the pathophysiology, treatment, prognosis and prevention of this disease, it seems that there is still a large gap between researchers, clinicians and patients [11-13].There are two points to note about this tough process of scrutiny of information, the first is that it remains difficult to reproduce the conditions that occur in clinical trials and apply them in everyday life; research is still focused on conventional rigid structure of the clinical trial, leaving out less conventional and strict pragmatic studies, but more focused on the health care of everyday patient; 1 in 1,000 published trials is a pragmatic study, leaving the more disadvantaged applicative vision of medical practice.

The second point, which goes along with this and is about the little interest that has led medical community to conduct studies on the quality of life topic, only just over $1 \%$ of the published articles are on this subject, advances have resulted in the need to evaluate changes in pathology and benefit the quality of life of patients when starting a new treatment, but much remains to cover.

New treatments can improve immunological, anatomical and functional aspects but not until a patient's perception about himself and his disease when the doctor changes the view as to the reality of treatment response. It is also important to assess the psychological environment of the patient, considering that it can act as a trigger for exacerbations and that these can lead to increased anxiety and an uncontrolled disease. Even today there is still much to understand disease especially in severe cases, however it is important that this knowledge be more useful, friendly and aimed at improving the patient care in the quality of life, not only at the molecular level.

\section{Reference}

1. Lawrence F (2014) Guidelines of care for management of atopic dermatitis. J Am Acad Dermatol 338-351.

2. Akdis C (2006) Diagnosis and Treatment of Atopic Dermatitis in Children and Adults: European Academy of Allergy and Clinical Immunology/American Academy of Allergy, Asthma and Immunology/PRACTALL Consensus Report. J Allergy Clin Immunol 118: 152-169.

3. Lewis S (2006) Quality of life and childhood atopic dermatitis: the misery of living with childhood eczema. Int J Clin Pract 60: 984-992.

4. Dong H (2012) Quality of Life and Disease Severity Are Correlated in Patients with Atopic Dermatitis. J Korean Med Sci, 27: 1327-1332.

5. Hani A (2010) The Impact of Childhood Atopic Dermatitis on Patients Family. Pediatric Dermatology, 27: 618-623.

6. William H (1999) World wide variations in the prevalence of symptoms of atopic eczema in the international study of asthma and allergies in childhood. J Allergy Clin Immunol, 103: 125-138.

7. Wolter S (2014) Atopic Dermatitis. Pediatr Clin N Am 61: 241-260.

8. Brandt E (2011) The cytocines and atopic dermatitis. J Clin Cell Immunol 2: 1-25.

9. Bogunnie wicz M (2011) Atopic Dermatitis: A disease of Altered of Skin Barrier and Immune Dysregulation. Immunol Rev 242: 233-246.

10. Lyons J (2015) Atopic Dermatitis in Children. Immunol Allergy Clin N Am 35: 161-183.

11. Naeyart J (1999) Cyclosporin in Atopic Dermatitis. Dermatology 198: $145-152$.

12. Khattri S (2014) Cyclosporine in patients with atopic dermatitis modulates activated inflammatory pathways and reverses epidermal pathology. J Allergy Clin Immunol 133: 1626 -1634.

13. Guttman E (2013) New Era of Biological Therapeutics in Atopic Dermatitis. Expert Opin Biol Ther 13 (4): 1-2. 